\title{
REVENDO ALGUNS DADOS DA HISTÓRIA DO JAPÃO
}

Tae Suzuki

RESUMO: O presente artigo apresenta alguns dados da história japonesa, consagrados por teses clássicas, que, com a colaboração principalmente da arqueologia, da sociologia, da antropologia e dos estudos de documentos de particulares tais como registros de diários, petições judiciais, anotações em versos de documentos, encontrados em depósitos, no verso de biombos e de portas corrediças, têm levado os historiadores a repensar questões básicas da própria história do Japão.

RÉSUMÉ: Ce travail présente certaines données de l'histoire japonaise, consacrées par des thèses classiques, qui à l'aide surtout de l'archeologie, de la sociologie, de l'antropologie et des études des documents des particuliers (diaries, petitions judiciales, notes au revers des documents trouvés en dépôts, au vers des paravents e des portes de papier), ont emmené des historiens à repenser certains aspects fondamentaux de l'histoire du Japon.

PALAVRAS-CHAVE: história do Japão, Antiguidade, período Chûsei

MOTS CLÉS: histoire du Japon, l'Antiquité, époque Chûsei

A análise de dados arqueológicos obtidos principalmente a partir da década de 50 e de estudos de documentos encontrados em forros de biombos e de portas corrediças, realizados nas últimas três décadas, vem desvendando fatos que, se não revertem a verdade histórica do Japão, têm contribuído para se repensá-la.

Durante séculos, veiculou-se a tese de um Japão isolado do continente asiático em seus primórdios, onde se desenvolveu uma cultura autóctone primitiva - a cultura Jômon (até o século III a.C.) - que, ao receber influências da cultura chinesa, via Coréia, 
sofre um avanço cultural e civilizatório considerável com a introdução da agricultura (notadamente a rizicultura) e do metal (ferro e bronze), avanço este que é expresso pela cultura Yayoi (séculos III a.C.-III d.C.); o intercâmbio cada vez mais intenso com a avançada civilização chinesa propiciou a formação de uma nação administrativa e politicamente organizada, eminentemente agrícola com base econômica na arrecadação de taxas e impostos calculados sobre a produção de arroz em terras que passaram a ser propriedade do Estado; com a privatização gradual das terras no correr da época Heian (séculos IX-XII), desenvolve-se uma economia diversificada, dando origem, por volta do século XIII a XIV, a mercados de troca de produtos excedentes e manufaturados, em torno dos quais se desenvolveram os centros urbanos. Estas são algumas das teses clássicas que apresentam temas hoje controversos e que tive a oportunidade de discutir e refletir com estudantes e professores do Nihon Jômin Bunka Kenkyûjo (Centro de Estudos da Cultura do Povo Japonês) da Universidade Kanagawa, durante os cursos e seminários ali realizados sob a orientação do Prof. Yoshihiko Amino, e sobre os quais passo a expor.

\section{O Homem Primitivo Civilizado do Periodo Jômon}

Para atender ao crescimento demográfico e tecnológico do Japão contemporâneo, a mão do homem feriu o solo para construir edifícios, abrir estradas, aeroportos, estações de trem e de metrô, e acabou encontrando ruínas arqueológicas que permitiram resgatar dados importantes sobre a vida e a cultura do homem primitivo japonês, derrubando por terra teses clássicas como a de que durante a época da cultura Jômon (até cerca do século III a.C.), o povo levava uma vida primitiva sustentada pela provisão das necessidades vitais pela caça, pesca e colheita de produtos in natura, desenvolvendo apenas o fabrico de armas e de utensílios de barro caracterizados pelas estampas feitas à corda (donde o nome jô "corda", mon "figura").

Tal tese sofre o primeiro abalo com a descoberta das ruínas de Korekawa (em Hachinohe, província de Aomori), em 1926, em camada geológica da época Jômon, onde foram encontrados objetos de barro e de madeira laqueados: espadas e flechas de barro para ornamento; brincos, braceletes, pentes e tijelas de madeira; utensílios de barro e de madeira, inclusive uma tijela com um pé de motivo vazado, uma técnica bastante avançada para os padrões culturais até então aceitos para a época. A laca sempre foi dada como introduzida da China da dinastia Han (séculos II a.C.-II d.C.) e a descoberta causou forte impacto entre os arqueólogos da época mas a falta de mais dados complementares acabou confinando o achado a um caso isolado, não merecendo a devida atenção do mundo científico de então. No entanto, descobertas de objetos semelhantes em escavações feitas em 1950, e notadamente a partir de 1970, vieram comprovar o uso da laca há muito mais tempo no Japão, remontando há cerca de seis milênios.

A laca não só passa de produto "importado" a produto nacional mas, principalmente, provoca a necessidade de se repensar toda a cultura Jômon levando-se em conta não só a variedade das técnicas necessárias para a obtenção do produto final, 
bem como a complexidade que cada uma dessas técnicas exige. É necessário, de um lado, produzir a tinta, o que implica extrair a seiva da urtiga - planta por si só difícil de ser manipulada devido a seu alto teor alérgico -, refinar, cozer e colorir que, por sua vez, exige a produção do corante; de outro, é preciso confeccionar o objeto de barro ou de madeira a ser laqueado, além de se proceder à laqueação que implica o mesmo hoje difícil processo de secagem para a obtenção de seu lustro característico.

É verdade que o domínio da técnica de laqueação, por si, não basta como prova da existência de uma divisão de trabalho por especialização técnica, mas não nos fica difícil aventar tal hipótese pelos processos tão diversos e complexos que ela implica. De qualquer forma, provavelmente já havia uma sociedade organizada, mesmo que rudimentarmente, o que fica mais evidente face a outras descobertas.

Grandes colunas de madeira, dispostas a distâncias regulares, foram encontradas nas ruínas da península Noto (Ichikawa) e de San'ai Maruyama (Aomori). Não se sabe ao certo qual era sua utilidade, se para moradia ou para ritos religiosos, mas sua regularidade atesta o conhecimento de uma forma de medida que só seria concebível em algum tipo de comunidade organizada. Já desenvolviam, provavelmente, o cultivo de cereais, haja vista a descoberta de sementes de cabaça, originária da Ásia tropical, além de arroz, sorgo, gergelim, não sendo, pois, de todo impossível a idéia de conhecimentos agrícolas que tenham permitido desenvolver a extração da seiva da urtiga para a obtenção da laca. É preciso considerar que a laca, apesar de suas técnicas complexas de produção, não contribuía para melhorar a produção agrícola, nem para facilitar as atividades de caça ou de pesca - atividades até então consideradas exclusivas do homem Jômon, sendo, pois, apreciada como um "objeto de arte" com ou sem fim mítico-religioso, o que só é concebível em sociedades mais desenvolvidas do ponto de vista cultural.

\section{A Cultura do Povo Bárbaro do Leste}

A influência da avançada cultura chinesa, introduzida massivamente no Japão a partir do século III a.C., desempenha um papel preponderante no desenvolvimento da cultura Yayoi (séculos III a.C. - III d.C.) a oeste do arquipélago. Novas técnicas de sericicultura, de tecelagem, de produção do sal, de manufatura de objetos de ferro e de bronze se expandiram rapidamente do norte da ilha de Kyûshû à região de Kinki (atual Nara, Kyôto e Osaka), onde se funda a sede de uma nação política e socialmente organizada nos fins do século VII. A rizicultura, por exemplo, atinge em cerca de 30 anos as regiões das baías de Ise (Mie) e de Wakasa(Fukui). O Mar do Japão e os rios da região foram as prováveis vias desse fluxo cultural, haja vista a distribuição de grande quantidade de ruínas da época ao longo desses cursos.

Essa onda cultural, no entanto, se interrompe na baía de Wakasa, a partir de onde se expande somente cerca de dois séculos depois. A leste viviam os emishi, povo inculto e bárbaro segundo a fonte histórica oficial, que foram sendo "dominados" por incursões armadas ao longo dos séculos, até aproximadamente o X. No entanto, torna-se cada vez mais sólida a tese de uma outra onda cultural introduzida no Japão pelo norte, 
desenvolvida principalmente nas regiōes nordeste (Tôhoku) e leste (Kantô). As dificuldades enfrentadas pela Corte de Yamato para dominar o povo dessas regiões provavelmente não se devem apenas a suas preocupações voltadas para a consolidação de seu poder, nem às barreiras naturais impostas pela própria geografia.

Pesquisas arqueológicas e genéticas apontam para a existência de elos culturais entre o norte da China e da Coréia com a região dos emishi já na época das grandes tumbas (kofun), do século III ao V. Na península de Noto (Ishikawa), foram descobertas tumbas com características da cultura Kohkuli, desenvolvida no norte da Coréia e nordeste da China do século I a.C. a VII d.C. São tumbas escavadas no solo, diferentes daquelas encontradas na região de Yamato, em montes de terra erguidos por mãos humanas sobre o chão. Outro vestígio do nordeste da China são as cavalgaduras encontradas nessas tumbas e que se ligam à criação de cavalos, muito difundida por volta dos séculos VIII e IX nas regiões Tôhoku e Kantô, onde a Corte de Yamato ia adquirir os rebanhos para suprir suas necessidades, conforme registros da época.

Havia, portanto, já desde o século III no mínimo, dois fluxos culturais diferentes: um a oeste, pela rota sul, via mar de Seto e norte de Kyûshû até Yamato, e outro a leste, pela rota norte, via Mar do Japão e, provavelmente, Hokkaido. Esses fluxos não se cruzam, ao menos de forma sistemática, até cerca do século XII a XIII, quando se dá, de fato, a expansão do domínio da corte de Kyôto pelo leste. Assim, por exemplo, na península de Tsugaru, no extremo norte da ilha de Honshû, até o séculos XII-XIII só existiam mura, "aldeias" unidades populacionais não abrangidas pelo sistema administrativo central cuja autoridade era exercida sobre os kuni (província), koori (distrito) e sato ou kyô (vila); na agricultura, observa-se a monocultura (arroz) a oeste e a policultura (amora, linho) a leste; uma pesquisa genética realizada por Aoba Takashi constatou a distribuição de nabos de origem chinesa e coreana a oeste, e de origem siberiana e européia a leste.

Dentre as culturas desenvolvidas nessa parte oriental e norte do arquipélago, citam-se: 1) a cultura Satsumon, difundida na ilha de Hokkaido e na região setentrional de Tôhoku por volta do século VIII ao XII, caracterizada pela técnica da pesca e pelo fabrico de utensílios de argila cinzenta, com parede interna negra, boca larga e base estreita onde se imprimiam traços à mão ou com penas de aves, donde o nome satsu, "impressão por pressão", mon, "motivo"; 2) uma cultura proveniente do mar de Okhotsk (do nordeste do continente até as ilhas Sakhalinas), de um povo exímio na arte da navegação e da pesca de grande porte, com influências marcantes na cultura ainu; 3 ) uma cultura com influências do sudeste asiático, haja vista as ruínas de fábricas de fundição encontradas na região meridional de Tôhoku, além das panelas de alça utilizadas pelos caçadores do sudeste asiático e distribuídas por toda a região que vai de Tôhoku a Kantô, avançando até a região central (Chûbu).

A ênfase dada ao grande intercâmbio entre Yamato, de um lado, e China e Coréia, de outro, que exerceu forte influência não só no modelo político-administrativo da Corte oficial japonesa como também em suas produções culturais, empanou por longo tempo a existência de um outro veio cultural a leste, de características próprias e também de grande ingerência na vida do povo da região. 


\section{Economia Monetária desde a Antiguidade}

Chûsei, literalmente "idade média" é a denominação comumente dada por historiadores japoneses ao longo período que vai do século XII ao XVI, compreendendo as épocas da instalação do primeiro xogunato (Kamakura), da divisão do governo central em cortes do sul e do norte (Nanbokuchô), do domínio do xogunato Ashikaga (Muromachi) e das lutas internas (Sengoku). O termo "idade média" no entanto, comporta valores políticos, sociais e econômicos próprios da história do Ocidente que, embora muitas vezes equiparáveis, nem sempre são coincidentes com os do Japão. Não sendo eu uma historiadora, deixo a discussão para os especialistas, adotando neste trabalho a própria denominação japonesa.

Esse período é marcado por grandes transformações sociais e políticas: por volta do século X a XI, inicia-se a derrocada do sistema ritsuryô (código de leis) de governo, que era sustentado pela arrecadação de taxas e impostos sobre a produção nas terras consideradas propriedades do Estado, propiciando o surgimento das propriedades privadas denominadas shôen; o monopólio do poder central conquistado pelo clã Fujiwara gera insatisfações entre os próprios nobres que acabam se radicando nas regiões para onde tinham sido enviados como representantes do governo (governadores, administradores locais, fiscais de arrecadação etc.) e se aliam aos donos de propriedades locais, tornando-se chefes (tôryô) de organizações armadas de onde surge a nova classe dos samurais; o poder político e social dessa classe emergente, inicialmente conquistada por aliança com facções da nobreza, se consolida com a criação dos xogunatos de Kamakura (séculos XII-XIII) e de Muromachi, em Kyôto (séculos XIV-XVI); a partir do século XV, começam as disputas entre clãs de samurais pela hegemonia política, que se alastram pelo país gerando um longo período de guerras internas até a unificação conseguida pelos Tokugawa, no início do século XVII.

Do ponto de vista da economia, o período Chûsei é dado como o do surgimento de mercados de troca $\mathrm{e}$ o aparecimento de centros urbanos com a consequente emergência da burguesia.

No entanto, as Crônicas de Weil, em seu capítulo "Sobre o povo de Wa"2, dizem:

É necessário cruzar os mares por mil $r i^{3}$ a leste da nação da soberana ${ }^{4}$ para se chegar a outras nações, todas do povo de Wa. [...] Campos não-irrigados e cultivados não são suficientes para suprir o povo de modo que eles vão ao norte e ao sul para comprar arroz [...] Cada nação tem mercados, sob a supervisão do daiố, onde produtos são trocados.

Tais citações não são de todo estranhas se se levar em conta que já havia, desde o período Jômon, uma diversidade de produção não só agrícola mas também de produtos manufaturados, com uma provável divisão de trabalho entre os habitantes das montanhas

1. Livro sobre a história de uma das três dinastias que dominaram a China no século III.

2. Nome pelo qual os chineses denominavam o Japão.

3. $1 \mathrm{ri}=3,9273 \mathrm{~km}$.

4. Provável referência à princesa Yamato Totohi Momoso Hime, irmã do décimo primeiro imperador Seijin.

5. Provável denominação do chefe local. 
e da costa litorânea. Assim, por exemplo, o sal que só podia ser obtido nas salinas dada a inexistência de salitres no solo japonês era consumido no interior do arquipélago, bem como os habitantes do litoral fabricavam utensilios de barro, de ferro e de bronze, produtos, ou extraídos de minérios, ou fabricados a alta combustão, para o que se torna necessária grande quantidade de madeira extraída das montanhas. A divisão de trabalho nas planícies se dá um pouco mais tardiamente, no período Yayoi, quando novas técnicas de agricultura introduzidas da China e da Coréia aumentam e diversificam o cultivo de produtos agrícolas, implementam-se a sericicultura, a tecelagem, a manufatura de utensílios de ferro e de bronze. A migração interna era intensa e não se torna difícil aventar a hipótese de um grande intercâmbio de produtos que consubstanciam a citação acima referida.

Assim, a permuta de produtos já era realizada desde o período Jômon, mercados surgem no período Yayoi e, no período das grandes tumbas, já nasce uma forma rudimentar de economia monetária em que 0 arroz era utilizado como unidade cambial. $\mathrm{O}$ arroz era considerado um produto sagrado haja vista a prática de se oferecer aos deuses a primeira colheita de arroz, cujas ramas eram depositadas em armazéns sob a guarda do chefe das comunidades. Na época do plantio, os lavradores recebiam uma parte desses grãos sagrados que se obrigavam a restituir na safra seguinte, acrescidos de um excedente a título de agradecimento aos deuses e que girava em torno de $50 \%$ da quantidade emprestada, não podendo exceder os $100 \%$. Dessa prática de fundo religioso, nasce o conceito econômico do empréstimo.

Por volta do século VIII, com a entrada em massa de moedas da China, a moeda começa a ser cunhada na região de Kinai onde se instalara a sede do governo. Com uma circulação apenas local e sua utilização mais para fins de magia ou de sortilégio, ela acaba desaparecendo depois que lhe atribuíram o mal pela epidemia que assolou a capital no século XII. Sua recuperação pelo mercado se dará somente por volta do século XIV, em substituição ao arroz, para atender mais prontamente ao mercado mais intenso que então se dava com o desenvolvimento de cidades em torno de castelos e nos pontos estratégicos de fluxos comerciais, agora bem mais diversificados e maiores.

\section{Hyakushô que Não É "Agricultor"}

Ao tomar a China como modelo para organizar de forma sistemática sua administração político-social, o governo japonês adota o sistema fundiário regido por um código de leis (ritsuryô), cujos alicerces repousam na instituição da população e das terras como propriedades do Estado. O erário passa a ser suprido pela arrecadação de taxas e impostos calculados sobre a produção de arroz nas terras públicas, distribuídas entre a população conforme o sexo, a idade e a classe social. Inicialmente instituído como arrecadação em arroz, tal medida não atende à realidade da época que já apresentava uma população economicamente ativa diversificada. Ao lado de uma maioria de camponeses, que se dedicava ao cultivo de arroz mas também de outros produtos como a amora, o linho, o sorgo etc., havia muitos pescadores, montanheses, artesãos das mais diferentes técnicas, mercadores, navegadores, que contribuíam com seus 
produtos de pesca, sal, madeira, carvão, seda, tecidos, produtos manufaturados. Já se procedia, como vimos, a uma intensa troca de produtos, escoados primordialmente por vias marítima e fluvial. E o arroz logo passa a ser adotado como unidade de conversão para os impostos e tributos pagos em produtos regionais ou manufaturados que, diga-se de passagem, constituíam uma parte significativa do erário nacional.

O arroz passa a ser adotado como unidade monetária pelas autoridades governamentais da época que, em nome do sucesso do plano econômico instituído, chegam a dar relevo excessivo à rizicultura a ponto de se criar uma forte consciência de nação eminentemente rizícola. Durante o governo do imperador Gensei (no poder, de 715 a 724), por exemplo, implantou-se, sem sucesso, um plano para cultivar cerca de 53 ha. (1 milhão de chôbu) de arrozais por ano, bem como se obrigou a população de Shima (península da baía de Ise, Mie), pescadora por excelência, a cultivar arrozais forçando-a a locar terras na vizinha província de Owari, pois suas terras eram impróprias à própria agricultura.

A concepção do arroz como padrão monetário perdura no correr dos séculos, mesmo depois que se propaga a circulação da moeda em âmbito nacional durante o período Chûsei e até mesmo no período Edo em que se desenvolveu a burguesia. Assim, o koku (medida de arroz equivalente a $180 \mathrm{l}$, calculada sobre a safra média de um arrozal) é adotado por Toyotomi Hideyoshi como unidade para os levantamentos sistemáticos das terras que ele implantou (taikôkenchi) nos fins do século XVI, a fim de poder avaliar e melhor exercer seu domínio sobre os feudos conquistados. O koku é também adotado pelo xogunato Tokugawa (séculos XVII-XIX) como medida padrão para o sistema chigyô, pelo qual os vassalos recebiam de seus senhores (daimio) terras em troca de taxas e o compromisso de fidelidade que se traduzia por prestação de serviços militares, inclusive gastos com armamentos, passando posteriormente a significar medida para a avaliação do poder econômico dos daimio e sua classificação hierárquica.

Apesar das mudanças políticas e econômicas, o arroz mantém um forte traço na cultura japonesa com reflexos no uso de alguns termos. Hyakushô, por exemplo, é hoje traduzido por nômin, "agricultor, lavrador" no linguajar comum. Mas se atentarmos a sua etimologia, o termo é formado por hyaku, "cem" e shô, a leitura chinesa de kabane, ou seja, títulos que a Corte de Yamato (séculos IV-VII), ao atrair os clãs mais poderosos da região para formar seu governo, atribuía-lhes inicialmente de acordo com seus cargos na hierarquia burocrática, passando posteriormente a atribuir conforme a atividade ou arte exercida por determinados clãs. $\mathrm{O}$ termo, portanto, em sua origem siginificava "centenas de artes ou atividades", isto é, "povo em geral de atividades várias", que nada tinha a ver com agricultores em particular.

Impõe-se, pois, uma leitura cuidadosa dos documentos antigos a fim de se evitar interpretações errôneas como a citada por Amino Yoshihiko (1991, p. 8), relativa aos dados apresentados nos livros de história para o nível colegial Shôsetsu nihonshi (ed. Yamakawa, 1991) e Shintei nihonshi (ed. Tokyo Shoseki, 1991). Para ilustrar que a população do período Edo (séculos XVII-XIX) era constituída por uma maioria de agricultores, ambos apresentam um gráfico em que consta 76,4\% de agricultores (nômin). Esses dados se baseiam em um estudo realizado por Sekiyama Naotarô sobre a 
distribuição populacional do feudo de Akita em 1849, em que consta 76,4\% de hyakushô. Os números são iguais mas muda a denominação de hyakushô para nômin nos livros didáticos.

Ainda nesse particular, cabe menção aos resultados obtidos pelos estudos que uma equipe de pesquisadores do Nihon Jômin Bunka Kenkyûjo (Centro de Estudos sobre a Cultura do Povo do Japão), da Universidade Kanagawa, vem realizando dos documentos guardados pela família Tokikuni desde o século XVI, quando se instalou na península de Noto, em Ishikawa. Sempre se teve a região como economicamente pobre, de pouca terra cultivável. $\mathrm{Na}$ base dessas considerações repousa o fato de que, desde o período Chûsei, e provavelmente desde a Antiguidade, era bem menor o percentual de impostos pagos em arroz relativamente aos pagos em outros produtos como seda, tecido, sal, ferro, óleo, papel, além do fato de sua população ser constituída em absoluta maioria por atamafuri, também denominado mizunomi, isto é, hyakushô que não eram proprietários de arrozais e não tinham kokudaka, ou seja, padrão para o cálculo do tributo anual pago em arroz (nengu) que, por sua vez, servia de termômetro para a avaliação do poder econômico de clãs e feudos.

Dentre os documentos analisados, foi encontrada uma grande quantidade de registros, diários, petições judiciais em forros de biombos e de portas corrediças, bem como no verso de documentos que, ao perderem sua validade, foram reaproveitados para tais registros pois o papel era um produto precioso na época. Uma leitura cuidadosa desses documentos revelou que a família Tokikuni, apesar de ser proprietária de terras com produção de $300 \mathrm{koku}$ (cerca de 54.000 litros de arroz/ano), explorava o sal, o carvão, a madeira, o minério e vivia essencialmente do comércio marítimo. Em 1619, era proprietária de quatro navios de 145 a 180 toneladas, com os quais percorria desde Matsumae (Hokkaido) até a ilha de Sado (Niigata), passando pelo lago Biwa até Otsu (Mie), Kyôto e Osaka explorando o comércio. Segundo os registros, levava o sal colhido em suas praias para o norte, de onde transportava algas para a região de Osaka e Kyôto. Constituíam também sua fonte de renda o carvão e a madeira retirados das montanhas de sua propriedade, o chumbo obtido da mina descoberta em 1618 na região e que ficou sob a administração da família. Não se pode obter a real dimensão do poder econômico dos Tokikuni se avaliada somente por sua produção de arroz, uma vez que, além de grande comerciante, provavelmente era também agente financeiro, na medida em que era responsável pelo depósito de produtos da região (kura), com autonomia para decidir sobre quais produtos dispor quando requisitada sua liberação pelo daimio, o que lhe dava a possibilidade de sua disposição para empréstimos particulares.

Assim como os Tokikuni, os hyakushô da região viviam, em sua maioria, de atividades não-agrícolas que lhes permitiam altas rendas, como comprovam dois outros documentos encontrados nessa busca. No verso do papel usado como forro de porta corrediça da mansão dos Tokikuni, foi encontrada uma petição ao daikan assinada por um hyakushô da aldeia de Sosogi denominado Enjirô que, devido ao desaparecimento do pai no mar a caminho de Matsumae, viu-se obrigado a assumir a dívida que o pai contraíra junto a comerciantes não só locais mas também das regiões próximas de Dewa (Yamagata, Akita) e Wakasa (Fukui) e solicita o parcelamento da dívida em cinqüenta prestações a serem debitadas de seus tributos anuais. A petição não faz menção à idade 
de Enjirô que, de repente, se torna arrimo de família com mãe e irmãos pequenos, mas dá a dimensão da dívida contraída que só é concebível onde haja grande capital de giro, mudando assim a concepção de Sosogi como uma aldeia produtora de sal e pobre.

Outro documento significativo é o registro, datado do século XVIII, de um empréstimo de alto vulto ( 100 ryô) feito aos Tokikuni por Shibakusaya, um comerciante marítimo da região com quem a família Tokikuni mantinha freqüentes contatos comerciais. $O$ dado comprova mais uma vez o poderio econômico de não-agricultores, donos de bens que permitiam empréstimos dessa monta. Mas o fato mais significativo é que Shibakusaya consta de registros de meados do século XVI como uma família de atamafuri, termo utilizado na região para mizunomi. Sempre traduzido por agricultores ou arrendatários pobres que não conseguiam produzir kokudaka suficiente para serem tributados, mizunomi inclui, no entanto, ricos comerciantes como os Shibakusaya.

De fato, um censo demográfico realizado em 1735 na região, registra um percentual de $71 \%$ de mizunomi contra $29 \%$ de agricultores com produção de 4 a 5 kokudaka, em sua maior aldeia Wajima, número aproximado registrado em outras aldeias da região como Ushitsu, Iida, Kabuto. O detalhamento desses mizunomi de Wajima registra artesãos, produtores de sômen (uma espécie de macarrão japonês), comerciantes e agentes marítimos, o que dá o perfil de sua população economicamente ativa. A região de Noto, portanto, não era uma região pobre, de poucas áreas cultiváveis como se supunha ser, ao contrário, era uma região economicamente rica, cuja população não necessitava de terras para cultivar uma vez que sua subsistência provinha de outros meios bastante rentáveis. Mizunomi eram, portanto, aqueles que não produziam o mínimo de arroz para ser tributado, entre os quais agricultores e arrendatários pobres, mas também ricos comerciantes que não produziam kokudaka simplesmente porque sua subsistência provinha de outros meios bastante rentáveis. E a região de Noto não era um região pobre, de poucas áreas cultiváveis, ao contrário, era uma região economicamente rica, cuja população não necessitava de terras para cultivar.

A história do Japão, como tantas outras, foi basicamente construída a partir de documentos oficiais das classes dirigentes que refletem marcadamente a ideologia nacional. Tais documentos revelam, sem dúvida, uma versão importante de sua realidade histórica mas a atenção voltada, nas últimas décadas, ao estudo de documentos de particulares, oficiais ou não, tem revelado dados que têm contribuído para um redimensionamento da história japonesa, ou consubstanciando a versão oficial até hoje largamente propalada, ou impondo uma reconsideração de alguns de seus aspectos.

Cumpre assinalar que mesmo uma boa parte desses documentos do povo (cartas, petições judiciais, diários ou registros particulares) dizem respeito a questões envolvendo a terra, inclusive naqueles referentes a litígios entre não-agricultores, o que se deve à proeminência dada à terra ao largo da história japonesa como base de cálculo de impostos e tributos. Mas a luz lançada sobre tantos documentos que se mantiveram guardadas sob a terra, nos depósitos ou nas dependências de moradias do povo em geral se torna significativa na medida em que levanta a hipótese, bastante plausível, do papel preponderante que as vias aquáticas - marítima, fluvial e lacustre - exerceram na vida política e social do Japão, haja vista sua própria geografia: um arquipélago constituído 
por mais de 3.700 ilhas, cerca de $28.000 \mathrm{~km}$ de costa litorânea e apenas $25 \%$ de solo cultivável. $\mathrm{O}$ governo adotou a terra como padrão de seu sistema político, mas boa parte do povo tinha na água a base de sua vida, usando-a como vias de fluxo econômico, político e cultural. Aventam-se, assim, as hipóteses de migraçōes do arquipélago para o continente asiático - e não apenas no sentido inverso - desde a era pré-histórica; da prática do comércio de produtos marítimos desde a Antiguidade; do desenvolvimento de uma economia monetária, ainda que rudimentar, mesmo antes da circulação efetiva da moeda. Essas e outras novas teses começam a ser desenvolvidas e consagradas com a contribuição de historiadores, antropólogos, etnólogos, sociólogos, lingüistas, até de geneticistas.

\section{Bibliografia}

AmINo, Yoshihiko. Nihon-no Rekishi-o Yominaosu (Relendo a História do Japão). Tóquio, Chikuma, 1995, $19^{\mathrm{a}} \mathrm{ed}$. Zoku Nihon-no Rekishi-o Yominaosu (Relendo a História do Japão), vol. 2. Tóquio, Chikuma, 1996. . Nihon Chûsei-no Minshûzô (O Perfil da Classe Plebéia da Época Chûsei), Iwanami Shinsho 136. Tóquio, Iwanami, 1983, $7^{\mathrm{a}} \mathrm{ed}$. . Higashi-to Nishi-no Kataru Nihon-no Rekishi (A História do Japão Contada pelo Leste e pelo Oeste). Tóquio, Société, 1993, $12^{\mathrm{a}}$ ed. . Chûsei Saikô (Repensando Chûsei). Tóquio, Editor's School, 1991, $7^{\mathrm{a}}$ ed. . Nihonron-no Shiza (Uma Perspectiva da Japonologia). Tóquio, Shogakkan.

KURODA, Toshio. Chûsei Minshû-no Sekai (O Mundo do Povo de Chûsei). Tóquio, Sanseido, $1991,3^{\text {a }}$ ed.

MiYamoto, Tsuneichi. Emakimono-ni Miru Nihon Shomin Seikatsushi (A Vida do Povo Japonês através dos Emaki). Chûkô Shinsho 605. Tóquio, Chûokôron, 1996, 19ª ed.

NaGaHARA, Keiji. Nihon Chûsei Shakaikôzôono Kenkyû (Estudos da Estrutura da Sociedade Chîsei). Tóquio, Iwanami, 1973.

OHNO, Susumu et al. Higashi Nihon-to Nishi Nihon (O Japão Ocidental e Oriental). Tóquio, Nihon Editor School, 1993, 6a ed.

Tae Suzuki

Centro de Estudos Japoneses da USP Curso de Língua e Literatura Japonesa - FFLCH-USP 